\title{
PERBEDAAN KARAKTERISTIK PENDERITA DIABETES MELITUS DENGAN KOMPLIKASI NEUROPATI YANG BEROBAT JALAN DI RSU ANUTAPURA PALU SETELAH 6 BULAN
}

\author{
Ruslan Ramlan Ramli ${ }^{1 *}$, Asrini Muslima Sari ${ }^{1}$, Amelia Hasanah ${ }^{1}$ \\ ${ }^{1}$ Program Studi pendidikan Dokter, Fakultas Kedokteran Universitas Alkhairaat, Jl. Diponegoro Palu \\ 94221, Sulawesi Tengah, Indonesia
}

*Corresponding author: Telp: +6282225257575, email: ramlanruslan@gmail.com

\begin{abstract}
ABSTRAK
Diabetes mellitus (DM) merupakan penyakit degeneratif yang diperkirakan akan terus meningkat prevalensinya. Diabetes melitus dengan komplikasi neuropati dapat mengganggu aktifitas kehidupan manusia yaitu dapat mengakibatkan ulkus pada kaki, amputasi, luka pada kulit yang sukar sembuh dan disfungsi seksual. Tujuan penelitian ini untuk mengetahui perbedaan gambaran karaktersitik sebelum dan setelah 6 bulan pada penderita diabetes melitus dengan komplikasi neuropati yang datang dan berobat jalan di Rumah Sakit Umum (RSU) Anutapura Palu. Metode penelitian adalah desktriptif analitik dengan desain cross sectional study. Pengumpulan data dilakukan dengan wawancara menggunakan kuesioner kepada semua pasien penderita diabetes melitus dengan komplikasi neuropati yang datang dan berobat jalan di RSU Anutapura Palu. Hasil penelitian menunjukkan bahwa Karakteristik pasien diabetes melitus dengan komplikasi neuropati yang datang dan berobat jalan di RSU Anutapura Palu yaitu jenis kelamin $(p=0,203)$ dan obesitas $(p=0,192) ; p>0,05$ tidak ditemukan perbedaan sebelum dan setelah 6 bulan kemudian pada pasien diabetes melitus dengan komplikasi neuropati yang datang berobat jalan di RSU Anutapura Palu. Karakteristik usia $(\mathrm{p}=0,00)$ dan lama menderita diabetes melitus $(p=0,00) ; p<0,05$ ditemukan perbedaan yang signifikan sebelum dan sesudah 6 bulan kemudian pada pasien diabetes melitus dengan komplikasi neuropati yang datang dan berobat jalan di RSU Anutapura Palu.
\end{abstract}

Kata Kunci: DM, Neuropati, RSU Anutapura

\section{ABSTRACT}

Diabetes mellitus (DM) is a degenerative disease which is expected to continue to increase in prevalence. Diabetes mellitus with complications of neuropathy can interfere with the activities of human life which can lead to foot ulcers, amputations, sores on the skin that are difficult to heal and sexual dysfunction. The purpose of this study was to determine differences in the characteristics of characteristics before and after 6 months in patients with diabetes mellitus with neuropathic complications who came and went outpatient at Anutapura General Hospital, Palu. The research method is descriptive analytic with cross sectional study design. Data collection was carried out by interview using a questionnaire to all patients with diabetes mellitus with complications of neuropathy who came and went outpatient at Anutapura General Hospital, Palu. The results showed that the characteristics of diabetes mellitus patients with neuropathic complications who came and went for outpatient treatment at Anutapura General Hospital in Palu were gender $(p=0.203)$ and obesity $(p=0.192) ; p>0.05$ no difference was found before and after 6 months later in patients with diabetes mellitus with neuropathic complications who came for outpatient treatment at Anutapura General Hospital, Palu. Age characteristics $(p=0.00)$ and duration of diabetes mellitus $(p=0.00) ; p<0.05$ found a significant difference before and after 6 months later in patients with diabetes mellitus with neuropathic complications who came and went outpatient at Anutapura General Hospital, Palu.

Keywords: DM, Neuropati, RSU Anutapura

\section{PENDAHULUAN}

Diabetes mellitus (DM) merupakan penyakit degeneratif yang diperkirakan akan terus meningkat prevalensinya. Sedangkan International Diabetes Federation memperkirakan pada 2030 jumlah penderita diabetes di seluruh dunia mencapai 450 juta orang, dimana $10-100 \%$ akan berkembang menjadi neuropati. ${ }^{1,2}$

Menurut hasil Riset Kesehatan Dasar (Riskesdas) tahun 2013, proporsi penduduk $\geq 15$ tahun dengan DM adalah 6,9\%. Prevalensi penderita DM berdasarkan wawancara (pernah 
didiagnosa dan ada gejala) mengalami peningkatan dari $1,1 \%$ (tahun 2007) menjadi $2,1 \%$ (tahun 2013). Prevalensi DM yang terdiagnosis dokter dan atau gejala, tertinggi terdapat di Sulawesi Tengah $(3,7 \%)$, Sulawesi Utara $(3,6 \%)$, dan Sulawesi Selatan $(3,4 \%)$. Proporsi penduduk umur $\geq 15$ tahun dengan toleransi glukosa terganggu (TGT) mencapai $29,9 \%$. Hal ini berarti akan semakin banyak penduduk yang berisiko tinggi untuk menderita DM. ${ }^{3}$

Provinsi Sulawesi Tengah dengan jumlah kasus baru yaitu penyakit Diabetes Mellitus tahun 2014 sebanyak 6.372 kasus, tahun 2015 sebanyak 11.210 kasus, tahun 2016 sebanyak 15.662 kasus. ${ }^{4}$ Sedangkan untuk Kota Palu sendiri jumlah kasus baru diabetes mellitus tahun 2015 sebanyak 3.011 kasus, tahun 2016 sebanyak 3.045 dan tahun 2017 sebanyak 3.117 kasus. ${ }^{5}$ Data dari Rumah Sakit Umum Anatapura Palu pada tahun 2012 pasien diabetes mellitus sebanyak 233 per tahunnya, 2013 sebanyak 240 per tahunnya, 2014 sebanyak 460 per tahunnya, 2015 sebanyak 248 orang per tahunnya, 2016 sebanyak 168 orang per tahunnya, dan 2017 sebanyak 147 orang per tahunnya. ${ }^{6}$

Orang yang hidup dengan DM tipe 2 lebih rentan terhadap berbagai bentuk komplikasi baik jangka pendek maupun jangka panjang, yang sering menyebabkan kematian dini dari mereka. Seringnya kejadian ini mengalami peningkatan morbiditas dan mortalitas yang terlihat pada pasien dengan DM tipe 2 karena asingnya pengetahuan tentang diabetes melitus. ${ }^{7}$

Penyakit diabetes melitus memiliki dua golongan komplikasi, yaitu komplikasi akut yang terdiri dari hipoglikemi dan hiperglikemi, serta komplikasi kronik yang terdiri dari komplikasi mikrovaskuler yakni neuropati, nefropati dan retinopati, serta komplikasi makrovaskuler yakni PJK, stroke dan penyakit pembuluh darah. Komplikasi neuropati yang merupakan komplikasi mikrovaskuler yang paling sering dan penting, dimana gejala yang timbul berupa hilangnya sensasi distal atau seperti kaki terasa terbakar dan bergetar sendiri ${ }^{8}$.

Komplikasi neuropati dapat mengakibatkan ulkus pada kaki, amputasi, luka pada kulit yang sukar sembuh dan disfungsi seksual. Komplikasi neuropati akan menghasilkan kehilangan sensasi pada kaki penderita diabetes melitus tipe 2, sehingga akan terjadi kalus, gangren, dan infeksi seperti selulitis ${ }^{9}$.

Diabetes melitus dengan komplikasi neuropati dapat mengganggu aktifitas kehidupan manusia. Komplikasi neuropati penting diketahui karena merupakan mikrovaskuler yang paling sering terjadi, sehingga perlu mengetahui gambaran komplikasi neuropati pada pasien diabetes melitus serta mengetahui perbedaan gambaran karaktersitik sebelum dan setelah 6 bulan pada penderita diabetes melitus dengan komplikasi neuropati yang datang berobat jalan di RSU Anutapura Palu.

\section{METODOLOGI}

Dalam penelitian ini menggunakan metode penelitian deskriptif analitik dengan pendekatan Cross Sectional. Populasi penelitian pada penelitian ini adalah semua pasien penderita diabetes melitus dengan komplikasi neuropati di RSU Anutapura palu. Subyek penelitian pada penelitian ini adalah pasien penderita diabetes melitus dengan komplikasi neuropati oleh dokter di RSU Anutapura Palu.

\section{Besar Sampel}

Besar sampel yang pasien penderita diabetes melitus dengan komplikasi neuropati oleh dokter di RSU Anutapura Palu selama 2 bulan. Pada bulan April dan Mei 2018, besar sampel Data Karakteristik Awal berjumlah 54 orang ${ }^{10}$, sedangkan setelah 6 bulan yaitu pada bulan Desember 2018 dan Januari 2019, besar dampel Data Karakteristik pasien berjumlah 45 orang $^{11}$.

\section{Cara Pengambilan Sampel}

Pengambilan sampel pada penelitian ini, menggunakan cara Consecutive sampling yaitu semua pasien yang didiagnosis menderita diabetes melitus dengan komplikasi neuropati di RSU Anutapura Palu yang memenuhi kriteria penelitian.

\section{Pengumpulan Data}

Pengumpulan data dilakukan dengan cara observasi wawancara langsung dan beberapa pemeriksaan klinis untuk mengisi case report. Data yang diperoleh berupa karakteristik pasien yaitu terdiri dari Jenis Kelamin, Usia, Lama menderita daiabetes melitus, dan Obesitas. 


\section{Analisis Data}

Untuk mengetahui perbedaan karakteristik pasien yang didiagnosis menderita diabetes melitus dengan komplikasi neuropati setelah 6 bulan digunakan uji Chi Square dengan batas kemaknaan $\alpha=5 \%$.

\section{HASIL DAN PEMBAHASAN}

HASIL

Jenis Kelamin

Perbedaan karakteristik penderita diabetes melitus dengan komplikasi neuropati berdasarkan jenis kelamin pada bulan april dan mei tahun 2018 dan setelah 6 bulan berikutnya dapat dilihat pada tabel berikut iniTabel 1 menunjukkan bahwa jumlah lakilaki pada bulan April dan mei 2018 yaitu 26 orang $(48,1 \%)$, sedangkan perempuan 28 orang $(51,9 \%)$. Setelah 6 bulan jumlah lakilaki yang datang berobat jalan di RSU Anutapura Palu yaitu 17 orang $(43,0 \%)$, sedangkan perempuan 28 orang $(62,2 \%)$.

Tabel 1 Perbedaan distribusi Jenis Kelamin Penderita diabetes melitus dengan komplikasi

Neuropati sebelum dan setelah 6 bulan

\begin{tabular}{ccccc}
\hline \multirow{2}{*}{$\begin{array}{c}\text { Penderita DM dengan Komplikasi } \\
\text { Neuropati }\end{array}$} & \multicolumn{2}{c}{ Jenis Kelamin } & \multirow{2}{*}{ Total } & \multirow{2}{*}{ P } \\
\cline { 2 - 3 } Data Awal (April dan Mei 2018) & $26(48,1 \%)$ & $28(51,9 \%)$ & \multirow{2}{*}{$54(100 \%)$} & \multirow{2}{*}{0,203} \\
\hline Setelah 6 Bulan & $17(37,8 \%)$ & $28(62,2 \%)$ & $45(100 \%)$ & \\
\hline Total & $43(43,4 \%)$ & $56(56,6 \%)$ & $99(100 \%)$ \\
\hline
\end{tabular}

Pada Tabel 1 dapat dilihat bahwa karakteristik penderita diabetes melitus dengan komplikasi neuropati lebih banyak ditemukan pada perempuan yaitu 52,9\% pada data awal yang dilaksanakan pada bulan arpil dan mei 2018 dan 62,2 \% setelah 6 bulan kemudian, namun tidak ditemukan perbedaan yang bermakna $(\mathrm{P}>0,05)$ antara data awal dan setelah 6 bulan dimana nilai $\mathrm{p}=0,203$. Artinya baik sebelum dan sesudah 6 bulan karakteristik jenis kelamin pasien diabetes melitus dengan komplikasi neuropati yang berobat jalan di RSU Anutapura Palu tidak berbeda secara signifikan.

\section{Usia}

Perbedaan karakteristik penderita diabetes melitus dengan komplikasi neuropati berdasarkan usia pada bulan april dan mei tahun 2018 dan setelah 6 bulan berikutnya dapat dilihat pada tabel berikut ini:

Tabel 2 Perbedaan distribusi Usia Penderita diabetes melitus dengan komplikasi Neuropati sebelum dan setelah 6 bulan

\begin{tabular}{|c|c|c|c|c|c|c|}
\hline \multirow[b]{2}{*}{$\begin{array}{c}\text { Penderita DM } \\
\text { dengan } \\
\text { Komplikasi } \\
\text { Neuropati }\end{array}$} & \multicolumn{4}{|c|}{ Usia } & \multirow[b]{2}{*}{ Total } & \multirow[b]{2}{*}{$\mathrm{P}$} \\
\hline & $\begin{array}{c}\text { Masa } \\
\text { Dewasa } \\
\text { Akhir (36- } \\
\text { 45 Tahun) } \\
\end{array}$ & $\begin{array}{c}\text { Masa Lansia } \\
\text { Awal (46-55 } \\
\text { Tahun) }\end{array}$ & $\begin{array}{c}\text { Masa Lansia } \\
\text { Akhir (56- } \\
65 \text { Tahun) }\end{array}$ & $\begin{array}{c}\text { Masa } \\
\text { Manula (65 } \\
\text { Tahun) }\end{array}$ & & \\
\hline $\begin{array}{c}\text { Data Awal (April } \\
\text { dan Mei 2018) }\end{array}$ & $\begin{array}{c}3 \\
(5.6 \%)\end{array}$ & $22(40.7 \%)$ & $17(31.5 \%)$ & $12(22.2 \%)$ & $\begin{array}{c}54 \\
(100 \%)\end{array}$ & \multirow{2}{*}{0,00} \\
\hline Setelah 6 Bulan & $\begin{array}{c}9 \\
(20 \%) \\
\end{array}$ & $30(66.7 \%)$ & $\begin{array}{c}2 \\
(4.4 \%)\end{array}$ & $\begin{array}{c}4 \\
(8.9 \%)\end{array}$ & $\begin{array}{c}45 \\
(100 \%)\end{array}$ & \\
\hline Total & $12(12,1 \%)$ & $52(52,5 \%)$ & $19(19,2 \%)$ & $16(16,2 \%)$ & $\begin{array}{c}99 \\
(100 \%)\end{array}$ & \\
\hline
\end{tabular}


Tabel 2 menunjukkan bahwa penderita diabetes melitus dengan komplikasi neuropati sebagian besar berkategori masa lansia awal dimana pada sebelum 6 bulan berjumlah 22 orang $(40,7 \%)$ dan setelah 6 bulan berjumlah 30 orang $(66,7 \%)$. Untuk karakteristik Usia, ditemukan perbedaan yang bermakna $(\mathrm{P}<0,05)$ antara data awal dan setelah 6 bulan dengan nilai $\mathrm{p}=0,00$. Artinya sebelum dan sesudah 6 bulan karakteristik usia pasien diabetes melitus dengan komplikasi neuropati yang berobat jalan di RSU Anutapura Palu terdapat perbedaan secara signifikan.

\section{Lama Menderita diabetes melitus}

Perbedaan karakteristik penderita diabetes melitus dengan komplikasi neuropati berdasarkan lama menderita diabetes melitus pada bulan april dan mei tahun 2018 dan setelah 6 bulan berikutnya dapat dilihat pada tabel berikut ini:

Tabel 3 Perbedaan distribusi lama penderita diabetes melitus dengan komplikasi Neuropati sebelum dan setelah 6 bulan

\begin{tabular}{ccccc}
\hline \multirow{2}{*}{$\begin{array}{c}\text { Penderita DM dengan Komplikasi } \\
\text { Neuropati }\end{array}$} & \multicolumn{2}{c}{ Lama Menderita DM } & \multirow{2}{*}{ Total } & \multirow{2}{*}{$\mathrm{p}$} \\
\cline { 2 - 3 } Data Awal (April dan Mei 2018) & $30(55,6 \%)$ & $24(44,4 \%)$ & $54(100 \%)$ & \multirow{2}{*}{0,00} \\
\hline Setelah 6 Bulan & $6(13,3 \%)$ & $39(86,7 \%)$ & $45(100 \%)$ & \\
\hline Total & $36(36,4 \%)$ & $63(63,6 \%)$ & $99(100 \%)$ & \\
\hline
\end{tabular}

Tabel 3 menunjukkan bahwa penderita diabetes melitus dengan komplikasi neuropati yang menderita diabetes melitus $<5$ Tahun pada bulan April dan Mei 2018 yaitu berjumlah 30 orang setelah 6 bulan kemudian jumlah orang yang menderita $<5$ Tahun yang berobat jalan menurun yaitu hanya berjumlah 6 orang. Penderita diabetes melitus $\geq 5$ Tahun pada bulan April dan Mei 2018 berjumlah 24 orang, setelah 6 bulan berikutnya pasien yang berobat jalan yang menderita diabetes melitus dengan komplikasi neuropati yaitu 39 orang. Pada Tabel 3 berdasarkan karakteristik lama menderita diabetes melitus, ditemukan perbedaan yang bermakna $(\mathrm{P}<0,05)$ antara data awal yaitu bulan April dan Mei 2018 dan setelah 6 bulan yaitu bulan Desember 2018 dan Januari 2019, dimana nilai $\mathrm{p}=0,00$. Artinya sebelum dan sesudah 6 bulan karakteristik lama menderita diabetes melitus pada pasien penderita diabetes melitus dengan komplikasi neuropati yang berobat jalan di RSU Anutapura Palu terdapat perbedaan secara signifikan.

\section{Obesitas}

Perbedaan karakteristik penderita diabetes melitus dengan komplikasi neuropati berdasarkan obesitas pada bulan april dan mei tahun 2018 dan setelah 6 bulan berikutnya dapat dilihat pada tabel berikut ini:

Tabel 4 Perbedaan distribusi obesitas penderita diabetes melitus dengan komplikasi Neuropati sebelum dan setelah 6 bulan

\begin{tabular}{ccccc}
\hline \multirow{2}{*}{\begin{tabular}{c} 
Penderita DM dengan Komplikasi $\begin{array}{c}\text { Obesitas } \\
\text { Neuropati }\end{array}$ \\
\cline { 2 - 4 }
\end{tabular}} & $\begin{array}{c}\text { Obesitas I, } \\
\text { Obesitas II }\end{array}$ & $\begin{array}{r}\text { Underweight, } \\
\text { Normoweight, } \\
\text { Overweight }\end{array}$ & Total & $\mathrm{p}$ \\
\hline Data Awal (April dan Mei 2018) & $16(29,6 \%)$ & $38(70,4 \%)$ & $54(100 \%)$ & \multirow{2}{*}{0,192} \\
\hline Setelah 6 Bulan & $18(40,0 \%)$ & $27(60,0 \%)$ & $45(100 \%)$ & \\
\hline Total & $34(34,3 \%)$ & $65(65,7 \%)$ & $99(100 \%)$ & \\
\hline
\end{tabular}


Tabel 4 menunjukkan bahwa penderita diabetes melitus dengan komplikasi neuropati yang obesitas tipe I atau obesitas tipe II pada bulan April dan Mei 2018 yaitu berjumlah 16 orang setelah 6 bulan kemudian jumlah orang yang menderita obesitas tipe I atau obesitas tipe II yang berobat jalan yaitu berjumlah 18 orang. Penderita diabetes melitus dengan komplikasi neuropati yang masuk dalam kategori underweight, normoweight, overweight pada bulan April dan Mei 2018 berjumlah 38 orang, setelah 6 bulan berikutnya berjumlah 27 orang. Total penderita diabetes melitus dengan komplikasi neuropati yang obesitas tipe I atau obesitas tipe II yaitu berjumlah 34 orang $(34,4 \%)$ dan total penderita diabetes melitus dengan komplikasi neuropati yang underweight, normoweight, dan overweight yaitu berjumlah 65 orang $(65,7 \%)$. Berdasarkan karakteristik obesitas, tidak ditemukan perbedaan yang bermakna $(\mathrm{P}>0,05)$ antara data awal yaitu bulan April dan Mei 2018 dan setelah 6 bulan yaitu bulan Desember 2018 dan Januari 2019 dengan nilai $\mathrm{p}=0,192$. Artinya baik sebelum dan sesudah 6 bulan karakteristik obesitas pada pasien diabetes melitus dengan komplikasi neuropati yang berobat jalan di RSU Anutapura Palu tidak berbeda secara signifikan.

\section{PEMBAHASAN}

\section{Jenis kelamin}

Penderita diabetes melitus dengan komplikasi neuropati berdasarkan distribusi jenis kelamin lebih banyak ditemukan pada perempuan yaitu 52,9 \% pada data awal yang dilaksanakan pada bulan april dan mei 2018 dan $62,2 \%$ setelah 6 bulan kemudian, namun tidak ditemukan perbedaan yang bermakna $(\mathrm{P}>0,05)$ antara data awal dan setelah 6 bulan dimana nilai $p=0,203$. Hasil penelitian sejalan dengan peneltian Hutapea, Kembuan, \& Maja (2016) yang menyatakan bahwa penderita neuropati diabetik mayoritas dialami oleh perempuan daripada laki-laki. ${ }^{12}$
Hasil penelitian tidak sejalan dengan penelitian Tanhardjo, Pinzon, \& Sari (2016) yang menyatakan bahwa kejadian neuropati diabetik paling banyak dialami oleh laki-laki daripada perempuan. Laki-laki dan perempuan memiliki risiko yang sama untuk terkena neuropati diabetik. ${ }^{13}$

\section{Usia}

Penderita diabetes melitus dengan komplikasi neuropati sebagian besar berkategori masa lansia awal dimana pada sebelum 6 bulan berjumlah 22 orang $(40,7 \%)$ dan setelah 6 bulan berjumlah 30 orang $(66,7 \%)$. Hal ini disebabkan karena pada usia ini terjadi penurunan fungsi organ. Hal tersebut sejalan dengan teori bahwa penuaan dapat menyebabkan resistensi insulin dan gangguan fungsi pankreas, sehingga penderita diabetes yang telah melewati masa dewasa berada pada risiko tinggi untuk mengalami komplikasi neuropati. ${ }^{14}$ Hasil penelitian ini juga menunjukkan bahwa kejadian komplikasi neuropati pada pasien diabetes melitus banyak pada kisaran usia lansia. ${ }^{15}$

\section{Lama menderita diabetes melitus}

Penderita diabetes melitus $\geq 5$ Tahun pada bulan April dan Mei 2018 berjumlah 24 orang, setelah 6 bulan berikutnya pasien yang berobat jalan yang menderita diabetes melitus dengan komplikasi neuropati yaitu 39 orang. Hal ini lebih banyak daripada penderita $<5$ Tahun, Neuropati diabetik atau penderita diabetes melitus dengan komplikasi neuropati umumnya terjadi setelah usia 5 tahun. Rendahnya kontrol glikemik dan dislipidemia akan meningkatkan terjadinya neuropati diabetik. ${ }^{16}$ Semakin lama mengalami diabetes melitus maka semakin tinggi pula kejadian komplikasi yang dialami. Durasi diabetes melitus tipe 2 dengan tingkat kadar gula darah yang tinggi akan memengaruhi perubahan dinding pembuluh darah. ${ }^{17}$ Tingginya kadar gula darah yang kronis menyebabkan penurunan 
sekresi insulin. Glukosa tersebut akan berubah menjadi sorbitol yang menyebabkan kerusakan sel saraf. Semakin lama seseorang menderita diabetes melitus maka proses ini akan berlangsung lebih lama dan memperparah terjadinya kerusakan sel saraf. $^{13}$

\section{Obesitas}

Total penderita diabetes melitus dengan komplikasi neuropati yang obesitas tipe I atau obesitas tipe II yaitu berjumlah 34 orang $(34,4 \%)$ dan total penderita diabetes melitus dengan komplikasi neuropati yang underweight, normoweight, dan overweight yaitu berjumlah 65 orang $(65,7 \%)$. Dalam hal ini terlihat bahwa tidak ada hubungan antara jumlah penderita diabetes melitus dengan komplikasi neuropati, dimana jumlah penderita keseluruhan adalah 99 orang namun, mayoritas penderita dengan keadaan bukan obesitas. Hal ini sesuai dengan teori penelitian oleh Wang et al (2014) juga menyebutkan tidak terdapat hubungan yang signifikan antara obesitas umum dan neuropati diabetik perifer. ${ }^{18}$ Penelitian lain yang dilakukan Tomic et al (2003) terhadap 156 responden menunjukkan peningkatan indeks massa tubuh atau obesitas diikuti dengan peningkatan prevalensi neuropati secara signifikan ${ }^{19}$.

Obesitas merupakan sindroma metabolik yang berhubungan dengan diabetes. Patofisiologi antara kedua faktor tersebut antara lain, yaitu resistensi insulin dan kekurangan insulin. Obesitas menyebabkan peningkatan kadar asam lemak bebas dalam plasma yang terusmenerus $^{20}$ karena jaringan adiposa yang membesar melepaskan lebih banyak asam lemak bebas dan pembersihan asam lemak bebas berkurang.$^{21}$ Sumber kelebihan asam lemak bebas pada individu obes dianggap sebagai asam lemak yang berasal dari makanan dan lipolisis jaringan adiposa. ${ }^{20}$

Sebagaimana neuropati, pasien diabetes dapat mengalami masalah sirkulasi kaki yang buruk, sebagai hasil kerusakan pembuluh darah. Masalah ini meningkatkan risiko ulserasi, infeksi dan amputasi. ${ }^{2}$ Terjadinya kerusakan mikrovaskular dapat dijelaskan melalui beberapa mekanisme. Pertama, obesitas berhubungan dengan stres oksidatif dan mengurangi ketersediaan asam nitrat sebagai mekanisme penting terjadinya penipisan mikrovaskular. Kedua, adiposit yang berlebihan berhubungan dengan inflamasi kronis vaskular; peningkatan kadar sitokin proinflamasi, terutama $\mathrm{TNF}$, dimana mempunyai hubungan negatif dengan proses penyembuhan kapiler kulit dan sensitivitas insulin. Ketiga, peningkatan massa lemak menyebabkan peningkatan kadar FFA terusmenerus dalam darah sehingga dapat mengganggu proses penyembuhan kapiler $^{20}$ dan menghambat induksi nitrat oksida serta peningkatan aliran darah. ${ }^{21}$

Nitrat oksida (NO) merupakan faktor utama relaksasi yang berasal dari endotelium yang menyebabkan vasodilatasi sehingga meningkatkan volume perfusi untuk memenuhi kebutuhan metabolisme yang meningkat. Pada obesitas, penurunan kadar NO telah diamati dan dapat menjelaskan gangguan dilatasi pembuluh darah. ${ }^{22}$

\section{KESIMPULAN}

Karakteristik pasien diabetes melitus dengan komplikasi neuropati yang datang dan berobat jalan di RSU Anutapura Palu yaitu jenis kelamin $(p=0,203)$ dan obesitas $(p=0,192)$; $\mathrm{p}>0,05$ tidak ditemukan perbedaan sebelum dan setelah 6 bulan kemudian pada pasien diabetes melitus dengan komplikasi neuropati yang datang dan berobat jalan di RSU Anutapura Palu. Karakteristik usia $(p=0,00)$ dan lama menderita diabetes melitus $(p=0,00) ; p<0,05$ ditemukan perbedaan yang signifikan sebelum dan sesudah 6 bulan kemudian pada pasien diabetes melitus dengan komplikasi neuropati yang datang berobat jalan di RSU Anutapura Palu. 


\section{DAFTAR PUSTAKA}

1. Standards of medical care in diabetes 2013. Diabetes Care. 2013. doi:10.2337/dc13-S011

2. International Diabetes Federation. IDF Diabetes Atlas 7th Edition Brussels, Belgium. $\quad 2015$. doi:10.1289/image.ehp.v119.i03

3. Dinas Kesehatan Republik Indonesia. Riset Kesehatan Dasar. Diabetes Mellit. 2013. doi:1 Desember 2013

4. Dinas Kesehatan Provinsi Sulawesi Tengah. In: ; 2016.

5. Dinas Kesehatan Kota Palu. In: ; 2017.

6. RSU Anutapura Palu.(2018).

7. Olokoba AB, Obateru OA, Olokoba LB. Type 2 diabetes mellitus: A review of current trends. Oman Med J. 2012. doi:10.5001/omj.2012.68

8. CDC. National Diabetes Fact Sheet. Centers Dis Control Prev US Dep Heal Hum Serv. 2011. doi:Centers for Disease Control and Prevention. National diabetes fact sheet: national estimates and general information on diabetes and prediabetes in the United States, 2011. Atlanta, GA: U.S. Department of Health and Human Services, Centers for Disease Con

9. Wu Y, Ding Y, Tanaka Y, Zhang W. Risk factors contributing to type 2 diabetes and recent advances in the treatment and prevention. Int J Med Sci. 2014. doi:10.7150/ijms. 10001

10. Sari AM, Ramli RR, Muchtar M. Faktor-Faktor Yang Ada Hubungan Dengan Derajat Nyeri Neuropati Pada Penderita Diabetes Mellitus Yang Berobat Jalan Di RSU Anutapura Palu Tahun 2018.; 2018.

11. Hasanah A, Kamissy S, Da Lima MR. Profil Penderita Diabetes Melitus Tipe 2 Dengan Komplikasi Neuropati Yang Rawat Jalan Di RSU Anutapura Palu.; 2019.

12. Hutapea FS, Kembuan MAHN, P.S. JM. Gambaran klinis neuropati pada pasien diabetes melitus di Poliklinik Neurologi RSUP Prof. Dr. R. D. Kandou periode Juli 2014 - Juni 2015. e-CliniC. 2016. doi:10.35790/ecl.4.1.2016.12115

13. Tanhardjo J, Pinzon RT, Sari LK. PERBANDINGAN RERATA KADAR HbA1c PADA PASIEN DIABETES MELITUS DENGAN NEUROPATI DAN TANPA NEUROPATI SENSORI MOTOR. Berk Ilm Kedokt Duta Wacana. 2016. doi:10.21460/bikdw.v1i2.13

14. Papatheodorou K, Papanas N, Banach M, Papazoglou D, Edmonds M. Complications of Diabetes 2016. J Diabetes Res. 2016. doi:10.1155/2016/6989453

15. Hutapea FS, Kembuan MA, Maja JP FKUSR. Gambaran klinis neuropati pada pasien diabetes melitus di Poliklinik Faisal S Hutapea 2 Mieke A. J e-Clinic. 2016.

16. Jaiswal $M$, Divers $J$, Isom $S$, et al. Prevalence and clinical correlates of diabetic peripheral neuropathy among youth with type 1 diabetes: Search for diabetes in youth cohort study. Diabetes. 2014.

17. Suyanto, Susanto A. Faktor-Faktor yang Berhubungan dengan Kejadian Neuropati Perifer Diabetik. $J$ Keperawatan dan Pemikir Ilm. 2016.

18. Wang DD, Bakhotmah BA, Hu FB, Ali Alzahrani H. Prevalence and correlates of diabetic peripheral neuropathy in a Saudi Arabic population: A crosssectional study. PLoS One. 2014. doi:10.1371/journal.pone.0106935

19. Tomić M, Poljičanin T, Pavlić-Renar I, Metelko Ž. Obesity - A risk factor for microvascular and neuropathic complications in diabetes? Diabetol Croat. 2003.

20. Verma S, Hussain ME. Obesity and diabetes: An update. Diabetes Metab Syndr Clin Res Rev. 2017. doi:10.1016/j.dsx.2016.06.017 
MEDIKA ALKHAIRAAT : JURNAL PENELITIAN KEDOKTERAN DAN KESEHATAN 2(1): 17-24

e-ISSN: 2656-7822, p-ISSN: 2657-179X

21. Boden G. Obesity, insulin resistance and free fatty acids. Curr Opin Endocrinol Diabetes Obes. 2011. doi:10.1097/MED.0b013e3283444b09

22. Boillot A, Zoungas S, Mitchell P, et al. Obesity and the Microvasculature: A Systematic Review and Meta-Analysis. PLoS One. 2013. doi:10.1371/journal.pone.0052708 